\title{
Effect of alkali metal ions on the formation mechanism of HCN during pyridine pyrolysis
}

\author{
Ji Liu $^{1} \cdot$ Wei Zhao $^{1} \cdot$ Xinrui Fan $^{1} \cdot$ Mingxin $\mathrm{Xu}^{1} \cdot$ Shu Zheng $^{1} \cdot{\text { Qiang } \operatorname{Lu}^{1}}^{1}$
}

Received: 13 September 2020/Revised: 9 November 2020/ Accepted: 25 March 2021/Published online: 16 April 2021

(C) The Author(s) 2021

\begin{abstract}
The catalytic effects of alkali metal ions $\left(\mathrm{Na}^{+}\right.$and $\left.\mathrm{K}^{+}\right)$on $\mathrm{NO}_{x}$ precursor formation during coal pyrolysis were investigated using the $\mathrm{N}$-containing compound pyridine as a model compound. Density functional theory calculations at the B3LYP/6-31G (d, p) level of theory were conducted to elucidate the mechanism of pyridine pyrolysis and the pathways for $\mathrm{HCN}$ formation. The calculation results indicate that $\mathrm{Na}^{+}$and $\mathrm{K}^{+}$have distinct influences on different pyrolysis reactions; these alkali metal ions facilitate the initial hydrogen transfer from $\mathrm{C}_{1}$ to $\mathrm{N}$ and $\mathrm{C}_{2}$, whereas they hinder the other hydrogen migration reactions. Both $\mathrm{Na}^{+}$and $\mathrm{K}^{+}$significantly reduce the activation energies for $\mathrm{C}-\mathrm{C}$ bond breakage and triple-bond formation, whereas they increase the activation energies for the isomerization reactions. The different effects essentially result from the distinct charge distributions induced by the two ions. Due to the distinct influences on the different reactions, the rate-determining steps are modulated, affecting the competitiveness of the different possible pathways of $\mathrm{HCN}$ formation. The formation of $\mathrm{HCN}$ from pyridine is promoted in the presence of $\mathrm{Na}^{+}$and $\mathrm{K}^{+}$because all the overall activation energies are decreased for different pathways. The calculation results agree well with previous experimental studies. Thus, the findings offer a new and promising approach to reveal the formation mechanism of $\mathrm{NO}_{x}$ and facilitate the control of $\mathrm{NO}_{x}$ for coal utilization.
\end{abstract}

Keywords Nitric oxide $\cdot$ Pyridine $\cdot$ Alkali metal ions $\cdot$ DFT $\cdot$ Catalysis $\cdot \mathrm{NO}_{x}$ precursor

\section{Introduction}

Nitrogen oxide $\left(\mathrm{NO}_{x}\right)$ emissions are predominantly ascribed to the combustion of fossil fuels, especially coal, and have generated severe adverse effects on the environment and human health (Kampa and Castanas 2008; Wu et al. 2010). In addition to generating acid rain, $\mathrm{NO}_{x}$ contributes significantly to the greenhouse effect: its greenhouse effect

Supplementary Information The online version contains supplementary material available at https://doi.org/10.1007/s40789021-00427-3.

Qiang Lu

qianglu@mail.ustc.edu.cn; qlu@ncepu.edu.cn

1 National Engineering Laboratory for Biomass Power Generation Equipment, North China Electric Power University, Beijing 102206, China is 260 times that of carbon dioxide (Tsiliyannis 2016; Chu et al. 2020). Thus, the emission of $\mathrm{NO}_{x}$ from coal utilization is a serious environmental concern. During the initial pyrolysis stage of coal combustion, organic N-containing compounds (mainly pyrrole, pyridine, and quaternary compounds) are first converted into small-molecule compounds (e.g., $\mathrm{NH}_{3}$ and $\mathrm{HCN}$ ), which can react with oxygen to form $\mathrm{NO}_{x}$ (Houser et al. 1980; MacNamara and Simmie 2003; Koger and Bockhorn 2005; Zhang et al. 2011; Ye et al. 2019). Both pyrrole and pyridine-based N-containing compounds have been widely used as model compounds to investigate the pyrolysis mechanisms (Liu and Guo 2017; Ma et al. 2019; Mai et al. 2020). Understanding the mechanisms of $\mathrm{NH}_{3}$ and $\mathrm{HCN}\left(\mathrm{NO}_{x}\right.$ precursors) formation from organic $\mathrm{N}$-containing compounds is critical to control $\mathrm{NO}_{x}$ emissions and has thus attracted widespread attention in recent decades. 
Both experimental and computational approaches have been widely applied to explore the pyrolysis mechanisms of various $\mathrm{N}$-containing compounds in coal, including pyridine and its derivatives (Hämäläinen et al. 1994; Molina et al. 2000; Adamczyk et al. 2014; Ikeda and Mackie 1995; Mackie et al. 1990; Hong et al. 2013; Ninomiya et al. 2000; Gu et al. 2013). HCN and cyanoacetylene have been detected as major products of the pyrolysis of pyridine and 2-methylpyridine, based on which Ikeda and Mackie (1995) developed a kinetic model to simulate pyrolysis reactions. Mackie et al. (1990) reported similar findings for pyridine pyrolysis under argon atmosphere. They proposed that the rupture of all $\mathrm{C}-\mathrm{H}$ bonds in the pyridine ring is feasible, especially the one at the ortho position of the nitrogen atom, which is weaker than the others. Hong et al. (2013) detected intermediates and products from pyridine pyrolysis using tunable synchrotron vacuum ultraviolet photoionization and molecular-beam mass spectrometry. Following the homolytic cleavage of the $\mathrm{C}-\mathrm{H}$ bond, $o-, p$-, and $m$-pyridyls were generated and then decomposed by breaking the pyridine ring. Among the pyridyl compounds, $m$-pyridyl was determined as the major source for $\mathrm{HCN}$ formation. Computational methods have also been applied to investigate the pyrolysis mechanism of pyridine. The semi-empirical PM3 calculations indicated that the $\mathrm{C}-\mathrm{H}$ bond of pyridine is broken to generate radicals; decomposition fragments are then successively generated by rupturing the weakest bonds of the radicals (Ninomiya et al. 2000). Gu et al. (2013) computationally studied the decomposition mechanism of pyridine using the B3LYP functional and 6-31G(d,p) basis set. They found that the breakage of the $\mathrm{C}-\mathrm{H}$ bond in pyridine preferentially produced the $o$-pyridyl radical. In addition, ring-opening via $\mathrm{C}-\mathrm{N}$ bond cleavage in the $o$-pyridyl radical was more favorable than ring-opening via $\mathrm{C}-\mathrm{C}$ bond cleavage, as indicated by the lower activation barrier of the former process. Meanwhile, our density functional theory (DFT) calculations indicated that the concerted hydrogen transfer is more feasible for the breakage of the $\mathrm{C}-\mathrm{H}$ bond than direct homolysis (Jiang et al. 2017; Liu et al. 2019; Liu et al. 2020a, b).

During the real coal pyrolysis/combustion process, the pyrolysis of pyridine and other $\mathrm{N}$-containing compounds can be affected by the other components in coal, such as metal ions. In addition, metal salts can be used to accelerate the process of coal gasification because the salt ions can create various active species by reacting with the carbonaceous material. Consequently, the effects of alkali metal ions on coal pyrolysis have been extensively studied. $\mathrm{Na}$ and $\mathrm{K}$ are the major ion-exchangeable alkali metals in low-rank coals, where they exist as carboxylates ($\left.\mathrm{COO}_{m} \mathrm{R}_{n}, \mathrm{R}=\mathrm{Na} / \mathrm{K}\right)$ or as soluble salts $\left(\mathrm{R}_{m} \mathrm{Cl}_{n}, \mathrm{R}=\mathrm{Na} / \mathrm{K}\right)$ (Liu et al. 2000). $\mathrm{Na}$ and $\mathrm{K}$ are easily volatilized during pyrolysis, which affects the evolution channels and the product distribution of coal (Durie 2013). Ohtsuka et al. (1997) found that the total conversion of coal-N to $\mathrm{NO}_{x}$ precursors ( $\mathrm{HCN}$ and $\mathrm{NH}_{3}$ ) and $\mathrm{N}_{2}$ strongly depended on the alkali metal ions at a high temperature of $1000{ }^{\circ} \mathrm{C}$. Franklin et al. (1983) investigated the roles of metal ions by pyrolyzing raw coal in the presence of calcium, sodium, and potassium under helium atmosphere at $1400 \mathrm{~K}$. They found that sodium and potassium ions had stronger effects on coal pyrolysis than calcium ion. This conclusion was supported by Wood and Sancier (1984), who found that alkali metal salts often had significant catalytic effects on pyrolysis reactions.

Currently, the mechanism of HCN formation from the pyrolysis of pure pyridine under uncatalyzed conditions has been comprehensively investigated; in contrast, few studies have reported the effects of alkali metal ions on the mechanism of pyridine pyrolysis. In this study, DFT calculations were conducted to investigate the catalytic effects of two typical alkali metal ions, $\mathrm{K}^{+}$and $\mathrm{Na}^{+}$, on the formation of $\mathrm{HCN}$ via pyridine pyrolysis.

\section{Calculation details}

All calculations were performed using Gaussian 16 (Frisch et al. 2016). Many studies have used DFT calculations to shed light on the pyrolysis chemistry of $\mathrm{N}$-containing compounds (e.g., pyrrole, indole, and pyridine) (Liu et al. 2018a, b, 2020). The stable geometries of all reactants, intermediates, transition states, and products were obtained through an initial unconstrained optimization using the B3LYP/6-31G (d, p) method. The geometries of the transition states were located using the TS (Berny) method, which has been confirmed to be accurate for the optimization of organic species (Liu et al. 2018a, b, 2020). In addition, according to Glukhovtsev et al. (1997), B3LYP calculations on iron-containing species gave reliable results comparable with experimental data. Basis set superposition error was also considered by examining the complexation energies of the $\mathrm{Na}^{+} / \mathrm{K}^{+}$-pyridine complexes. The results indicate that the method employed in the present work is suitable to explore interactions between pyridine and $\mathrm{Na}^{+}$/ $\mathrm{K}^{+}$(Table S1 in Supplementary Material).

All optimized geometry configurations were further examined by frequency analysis at the same computational level. The vibrations were checked with the aid of the visualization software GaussView 6.0 (Dennington et al. 2016). The reactants, intermediates, and products were verified as the local minima with no imaginary frequencies, while all transition states were confirmed to be first-order saddle points having one imaginary frequency. The corresponding minima and first-order saddle points were verified 
to be on the same potential energy surface by conducting intrinsic reaction coordinate calculations at the same computational level. The enthalpies at $298.15 \mathrm{~K}$ and $1 \mathrm{~atm}$ were determine to discuss the energetics (Ling et al. 2009; Beste and Buchanan 2009; Liu et al. 2018a; Liu et al. $2020 \mathrm{a}, \mathrm{b})$. The activation energy was defined as the difference in enthalpy or Gibbs free energy (shown in Supplementary Material) between the reactants and the relevant transition state (Glukhovtsev et al. 1997).

\section{Results and discussion}

In our previous investigation, DFT calculations were conducted to investigate the possible pathways of $\mathrm{HCN}$ formation during pyridine pyrolysis under uncatalyzed conditions. Pyridine tends to decompose via the initial hydrogen transfer process, as shown in Figure S1 in Supplementary Material. According to our preliminary work, the pyrolysis of pyridine to form $\mathrm{HCN}$ can proceed via five pathways (Fig. 1): path-a, path-b, path-c, path-d, and pathe. Based on the DFT calculation results, the effects of $\mathrm{Na}^{+}$ and $\mathrm{K}^{+}$on the initial hydrogen transfer and the formation of $\mathrm{HCN}$ are discussed in Sects. 3.1 and 3.2, respectively.

\subsection{Effects of $\mathrm{Na}^{+}$or $\mathrm{K}^{+}$on the initial hydrogen transfer reactions}

Table 1 summarizes the activation energies of the initial hydrogen transfer reactions under the uncatalyzed and
$\mathrm{Na}^{+} / \mathrm{K}^{+}$-catalyzed conditions. The two alkali metal ions have different influences on the five sites of hydrogen transfer. The removal of $\mathrm{H}$ from $\mathrm{C}_{1}$ (Reactions a and $\mathrm{b}$ ) is promoted by $\mathrm{Na}^{+}$and $\mathrm{K}^{+}$. For Reaction a, $\mathrm{Na}^{+}$decreases the activation energy to a greater extent than $\mathrm{K}^{+}$, whereas the opposite is true for Reaction b. Notably, the activation energy for the hydrogen transfer from $\mathrm{C}_{1}$ to $\mathrm{C}_{2}$ (Reaction $\mathrm{b}$ ) decreases by 69.4 and $71.9 \mathrm{~kJ} / \mathrm{mol}$ in the presence of $\mathrm{Na}^{+}$ and $\mathrm{K}^{+}$, respectively. The differences in the activation energy for Reaction a $\left(\mathrm{C}_{1}\right.$ to $\left.\mathrm{N}\right)$ are less than $10 \mathrm{~kJ} / \mathrm{mol}$ for the uncatalyzed and ion-catalyzed conditions. Other hydrogen transfer reactions are hindered in the presence of alkali metal ions, and the inhibition effect is stronger in the presence of $\mathrm{Na}^{+}$than that of $\mathrm{K}^{+}$. The above results indicate that alkali metal ions affect the decomposition of pyridine and the formation of $\mathrm{HCN}$ by influencing the initial hydrogen transfer process, with $\mathrm{Na}^{+}$having a greater influence than $\mathrm{K}^{+}$. Among the five hydrogen transfer reactions, Reaction $b$ is the most feasible in the presence of alkali metal ions, whereas Reaction a is dominant under uncatalyzed conditions. The detailed effects of alkali metal ions on the pathways of $\mathrm{HCN}$ formation are discussed below.

\subsection{Effects of $\mathrm{Na}^{+}$and $\mathrm{K}^{+}$on the pathways of $\mathrm{HCN}$ formation}

While the presence of metal ions does not change the possible pathways of $\mathrm{HCN}$ formation from pyridine, it does affect the geometries of the transition states and

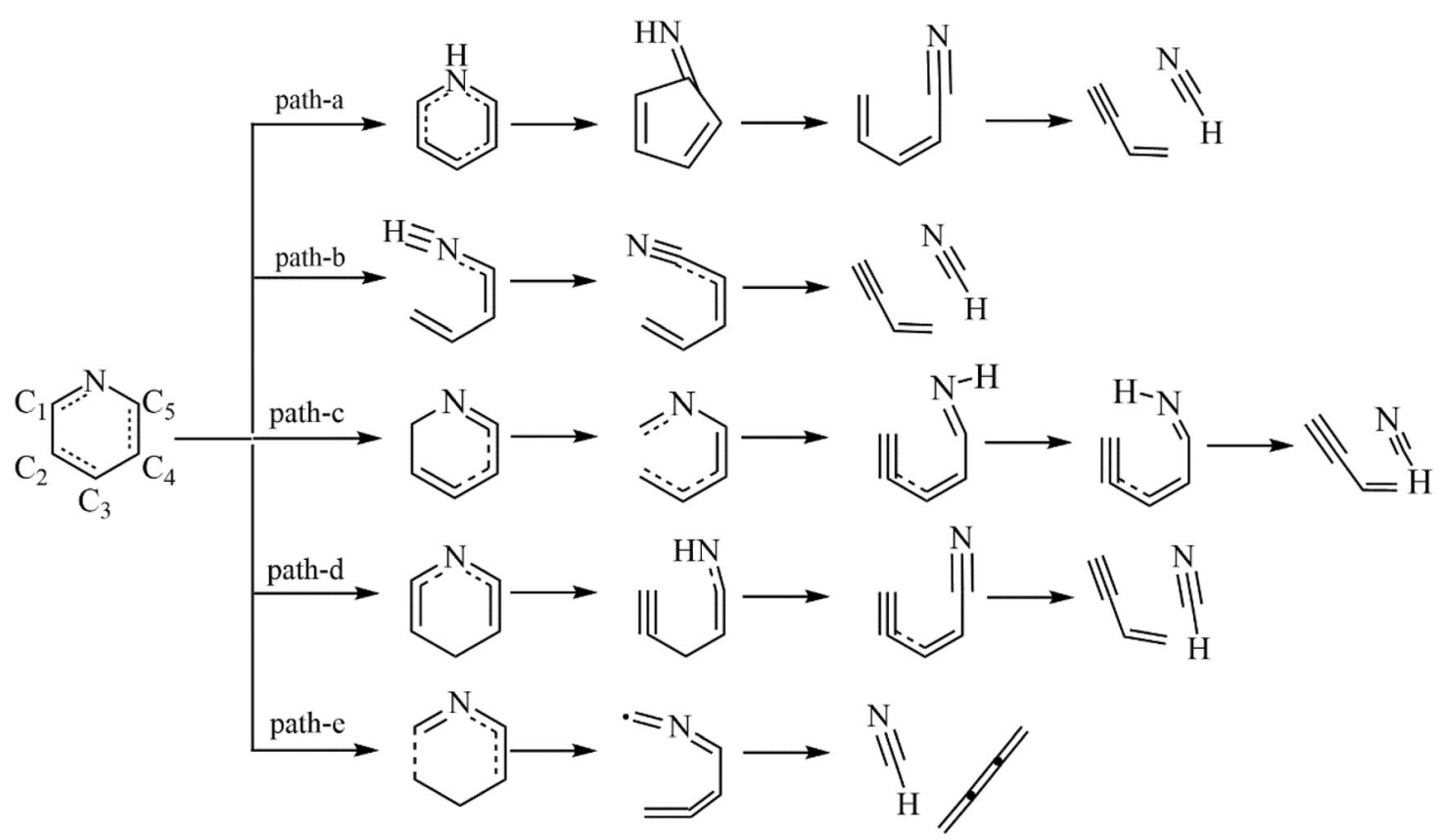

Fig. 1 Scheme showing the possible pathways of $\mathrm{HCN}$ formation during pyridine pyrolysis 
Table 1 Comparison of the activation energies for the initial hydrogen transfer in the absence and presence of $\mathrm{Na}^{+}$or $\mathrm{K}^{+}$

\begin{tabular}{|c|c|c|c|c|c|}
\hline Hydrogen transfer sites & $\begin{array}{l}\mathrm{C}_{1} \text { to } \mathrm{N} \\
\mathrm{H}\end{array}$ & $\begin{array}{l}\mathrm{C}_{1} \text { to } \mathrm{C}_{2} \\
\mathrm{H}-\mathrm{T}\end{array}$ & $\mathrm{C}_{2}$ to $\mathrm{C}_{1}$ & $\mathrm{C}_{2}$ to $\mathrm{C}_{3}$ & $\mathrm{C}_{3}$ to $\mathrm{C}_{2}$ \\
\hline \multicolumn{6}{|c|}{ Activation energies $(\mathrm{kJ} / \mathrm{mol})$} \\
\hline Uncatalyzed & 357.7 & 413.9 & 389.6 & 406.6 & 389.4 \\
\hline $\mathrm{Na}^{+}$-catalyzed & 349.6 & 344.5 & 411.0 & 423.0 & 423.4 \\
\hline $\mathrm{K}^{+}$-catalyzed & 354.4 & 342.0 & 404.7 & 419.5 & 418.0 \\
\hline
\end{tabular}

intermediates. The detailed pathways are compared below. In this section, the letters " $n$ " and " $k$ " are used to represent the presence of $\mathrm{Na}^{+}$and $\mathrm{K}^{+}$, respectively, and the transition states and intermediates are respectively distinguished by the letters " $t$ " and " $m$ ". For example, "a-n-1t" represents the first transition state of path-a in the presence of $\mathrm{Na}^{+}$.

\subsubsection{HCN formation via path-a}

The energy profiles for HCN formation via path-a with and without catalysis are depicted in Fig. 2. As discussed above, the decomposition of pyridine begins with the transfer of hydrogen from $\mathrm{C}_{1}$ to $\mathrm{N}$, disturbing the stability of the $\mathrm{N}$-heterocycle. The transition states a-1t, a-n-1t, and a-k-1t are involved in this step for the uncatalyzed, $\mathrm{Na}^{+}$catalyzed, and $\mathrm{K}^{+}$-catalyzed conditions with activation energies of $357.7,349.6$, and $354.4 \mathrm{~kJ} / \mathrm{mol}$, respectively. Subsequently, the six-membered intermediate a-1 $\mathrm{m}$ isomerizes into the five-membered ring a- $2 \mathrm{~m}$ via the simultaneous cleavage of the $\mathrm{C}_{1}-\mathrm{N}$ bond and generation of the $\mathrm{C}_{1}-\mathrm{C}_{6}$ bond. The presence of $\mathrm{Na}^{+}$or $\mathrm{K}^{+}$increases the activation energy from 462.2 to 468.1 or $470.2 \mathrm{~kJ} / \mathrm{mol}$, respectively. Thus, $\mathrm{Na}^{+}$and $\mathrm{K}^{+}$inhibit the isomerization

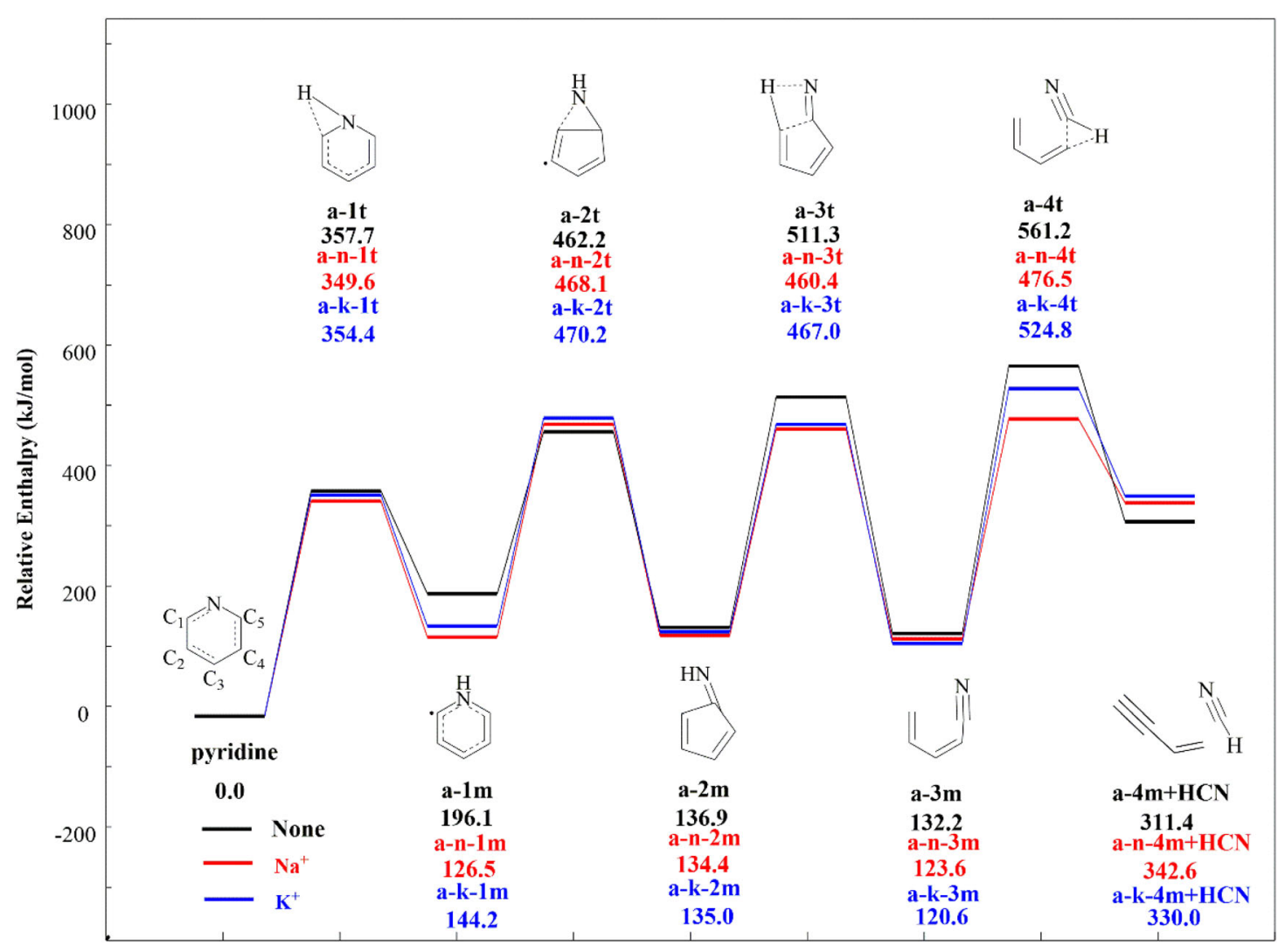

Fig. 2 Energy profiles of uncatalyzed and $\mathrm{Na}^{+} / \mathrm{K}^{+}$-catalyzed pyridine pyrolysis to form $\mathrm{HCN}$ via path-a (unit: $\mathrm{kJ} / \mathrm{mol}$ ) 
reaction of the pyridine ring, and $\mathrm{K}^{+}$has a stronger effect than $\mathrm{Na}^{+}$.

Subsequently, the five-membered ring of intermediate $\mathrm{a}-2 \mathrm{~m}$ is cleaved via a concerted ring-opening reaction in which the $\mathrm{C}=\mathrm{N}$ double bond becomes a triple bond. This step has an activation energy of $511.3 \mathrm{~kJ} / \mathrm{mol}$ without catalysis. For $\mathrm{Na}^{+}$- and $\mathrm{K}^{+}$-catalyzed pyridine pyrolysis, the activation energies of this ring opening are 460.4 and $467.0 \mathrm{~kJ} / \mathrm{mol}$, respectively. This indicates that $\mathrm{Na}^{+}$and $\mathrm{K}^{+}$ can significantly reduce the activation energy for the concerted ring-opening reaction of pyridine derivatives by $\sim$ $50 \mathrm{~kJ} / \mathrm{mol}$. Finally, the $\mathrm{C}_{4}-\mathrm{C}_{5}$ bond of intermediate a-3 m is cleaved via hydrogen transfer from $\mathrm{C}_{4}$ to $\mathrm{C}_{5}$, producing a-4 $\mathrm{m}$ (vinylacetylene) and $\mathrm{HCN}$. The final step has an activation energy of $561.2 \mathrm{~kJ} / \mathrm{mol}$ under the uncatalyzed condition. The addition of $\mathrm{Na}^{+}$or $\mathrm{K}^{+}$lowers the activation energy by 84.7 or $36.4 \mathrm{~kJ} / \mathrm{mol}$, respectively, showing that $\mathrm{Na}^{+}$and $\mathrm{K}^{+}$promote the breakage of the $\mathrm{C}-\mathrm{C}$ bond to form $\mathrm{HCN}$. Moreover, $\mathrm{Na}^{+}$has a greater effect than $\mathrm{K}^{+}$in this step. Notably, the final step is the rate-determining step in path-a regardless of the presence of alkali metal ions; the overall activation energies are 561.2, 476.5, and $524.8 \mathrm{~kJ} / \mathrm{mol}$ for the uncatalyzed, $\mathrm{Na}^{+}$-catalyzed, and $\mathrm{K}^{+}$catalyzed conditions, respectively.

In summary, alkali metal ions $\left(\mathrm{Na}^{+}\right.$and $\left.\mathrm{K}^{+}\right)$can significantly promote the concerted ring-opening and final hydrogen transfer in path-a. These two reaction steps both involve $\mathrm{C}-\mathrm{C}$ bond rupture. In comparison, the isomerization reaction and initial hydrogen transfer in path-a are less affected by the two alkali metal ions. $\mathrm{Na}^{+}$and $\mathrm{K}^{+}$lower the overall activation energy to promote $\mathrm{HCN}$ generation via path-a, with $\mathrm{Na}^{+}$having a stronger catalytic effect than $\mathrm{K}^{+}$.

\subsubsection{HCN formation via path-b}

The effects of alkali metal ions on the pyrolysis of pyridine in path-b are shown in Fig. 3. The initial hydrogen transfer from the $C_{1}$ position to the $C_{2}$ position is unique in comparison with the initial hydrogen transfer steps in the other pathways. The $\mathrm{N}$-heterocycle is cleaved via $\mathrm{C}_{1}-\mathrm{C}_{2}$ bond cleavage, which is accompanied by the hydrogen transfer. As stated above, this reaction is facilitated by the presence of alkali metal ions. The activation energies are 413.9, 344.5 , and $342.0 \mathrm{~kJ} / \mathrm{mol}$ for the uncatalyzed, $\mathrm{Na}^{+}$-catalyzed, and $\mathrm{K}^{+}$-catalyzed conditions. Subsequently, the intermediate $\mathrm{b}-1 \mathrm{~m}$ undergoes isomerization via the simultaneous formation of the $\mathrm{C}_{1}-\mathrm{C}_{5}$ bond and breaking of the $\mathrm{C}_{5}-\mathrm{N}$ bond. The activation energy of this step is $371.5 \mathrm{~kJ} / \mathrm{mol}$ under the uncatalyzed condition. During catalytic pyridine pyrolysis, the activation energies of the transition states are 395.0 and $389.9 \mathrm{~kJ} / \mathrm{mol} \mathrm{Na}^{+}$and $\mathrm{K}^{+}$, respectively, 23.5 and $18.4 \mathrm{~kJ} / \mathrm{mol}$ higher than the corresponding activation energy without alkali metal ions, respectively. This result shows that $\mathrm{Na}^{+}$and $\mathrm{K}^{+}$inhibit the isomerization reaction of the pyridine ring, and that $\mathrm{Na}^{+}$ has a slightly stronger effect than $\mathrm{K}^{+}$. Finally, the newly formed $\mathrm{C}_{1}-\mathrm{C}_{5}$ bond is cleaved through a hydrogen transfer reaction to produce b-3 m (vinylacetylene) and $\mathrm{HCN}$. Without catalysis, the activation energy of this step is $561.2 \mathrm{~kJ} / \mathrm{mol}$, and it is the rate-determining step of path-b. In the presence of $\mathrm{Na}^{+}$and $\mathrm{K}^{+}$, the activation energy is decreased by 84.7 and $36.4 \mathrm{~kJ} / \mathrm{mol}$, respectively. Even so, this process is still the rate-determining step under the $\mathrm{Na}^{+}$- and $\mathrm{K}^{+}$-catalyzed conditions.

In summary, the two alkali metal ions promote the formation of $\mathrm{HCN}$ by significantly reducing the overall activation energy in path-b. The overall catalytic abilities of the two alkali metal ions are similar, with $\mathrm{K}^{+}$having a slight advantage over $\mathrm{Na}^{+}$. As expected, the two alkali metal ions promote the breakage of $\mathrm{C}-\mathrm{C}$ bonds during step 1 and step 3 of path-b.

\subsubsection{HCN formation via path-c}

Figure 4 shows the energy profiles of path-c under the uncatalyzed and alkali metal ion-catalyzed conditions. The hydrogen transfer from $\mathrm{C}_{2}$ to $\mathrm{C}_{1}$ initiates the decomposition of pyridine in path-c. Under the uncatalyzed condition, transition state $\mathrm{c}-1 \mathrm{t}$ is involved with an activation energy of $389.6 \mathrm{~kJ} / \mathrm{mol}$. Under the catalysis of $\mathrm{Na}^{+}$and $\mathrm{K}^{+}$, transition states c-n-1t and c-k-1t are involved, and the activation energy is increased by 21.4 and $15.1 \mathrm{~kJ} / \mathrm{mol}$, respectively. Hence, both $\mathrm{Na}^{+}$and $\mathrm{K}^{+}$hinder internal hydrogen transfer $\left(\mathrm{C}_{2}\right.$ to $\left.\mathrm{C}_{1}\right)$, with $\mathrm{Na}^{+}$having a slightly greater effect than $\mathrm{K}^{+}$. Following the initial hydrogen transfer, the $\mathrm{H}$ at $\mathrm{C}_{1}$ migrates to the $\mathrm{N}$ atom $(485.1 \mathrm{~kJ} / \mathrm{mol})$ under the uncatalyzed condition. The activation energy of this step is increased to 535.2 and $527.6 \mathrm{~kJ} / \mathrm{mol}$ under the catalysis of $\mathrm{Na}^{+}$and $\mathrm{K}^{+}$, respectively.

Different from path-a, the intermediate c- 2 m undergoes ring opening to break the $\mathrm{C}_{1}-\mathrm{N}$ bond without the involvement of a five-membered intermediate. The activation energy decreases slightly from $359.0 \mathrm{~kJ} / \mathrm{mol}$ (uncatalyzed) to $355.6\left(\mathrm{Na}^{+}\right.$-catalyzed) and $354.2 \mathrm{~kJ} / \mathrm{mol}\left(\mathrm{K}^{+}\right.$catalyzed). Subsequently, the $\mathrm{N}-\mathrm{H}$ bond rotates into a proper position for the final hydrogen transfer from the $\mathrm{N}$ atom to the $\mathrm{C}_{4}$ position. Finally, the concerted cleavage of the $\mathrm{C}_{4}-\mathrm{C}_{5}$ bond leads to the production of $\mathrm{HCN}$ and b-5 m (vinylacetylene). The presence of $\mathrm{Na}^{+}$or $\mathrm{K}^{+}$greatly decreases the activation energy of the final hydrogen transfer from $687.4 \mathrm{~kJ} / \mathrm{mol}$ (uncatalyzed) to $503.0 \mathrm{~kJ} / \mathrm{mol}$ $\left(\mathrm{Na}^{+}\right.$-catalyzed) or $516.6 \mathrm{~kJ} / \mathrm{mol}\left(\mathrm{K}^{+}\right.$-catalyzed). Thus, $\mathrm{Na}^{+}$has a greater promotion effect than $\mathrm{K}^{+}$in this step.

According to the above results, the rupture of $\mathrm{C}-\mathrm{C}$ bonds in the ring-opening and final hydrogen transfer 


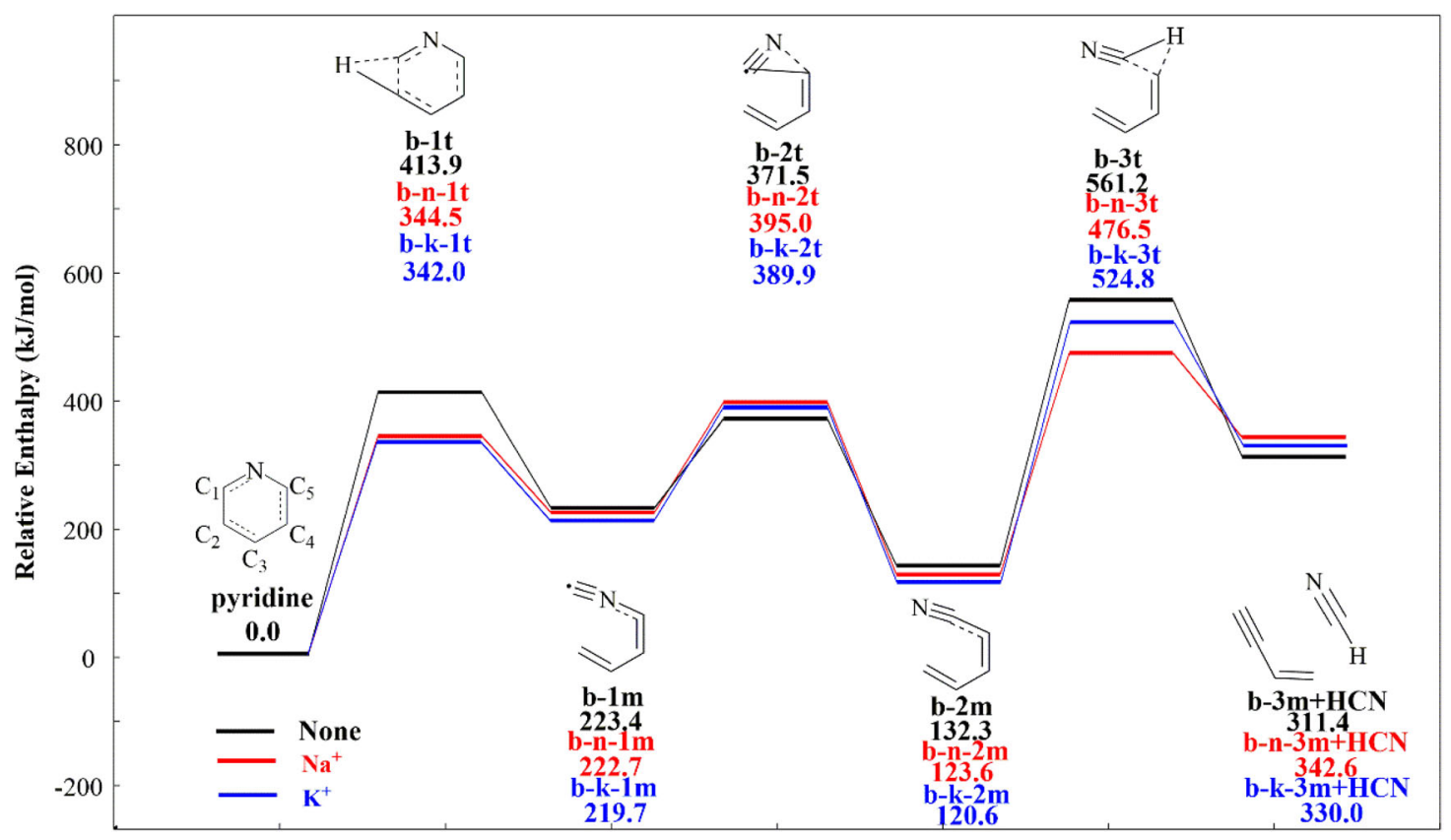

Fig. 3 Energy profiles of uncatalyzed and $\mathrm{Na}^{+} / \mathrm{K}^{+}$-catalyzed pyridine pyrolysis to form $\mathrm{HCN}$ via path-b (unit: $\mathrm{kJ} / \mathrm{mol}$ )

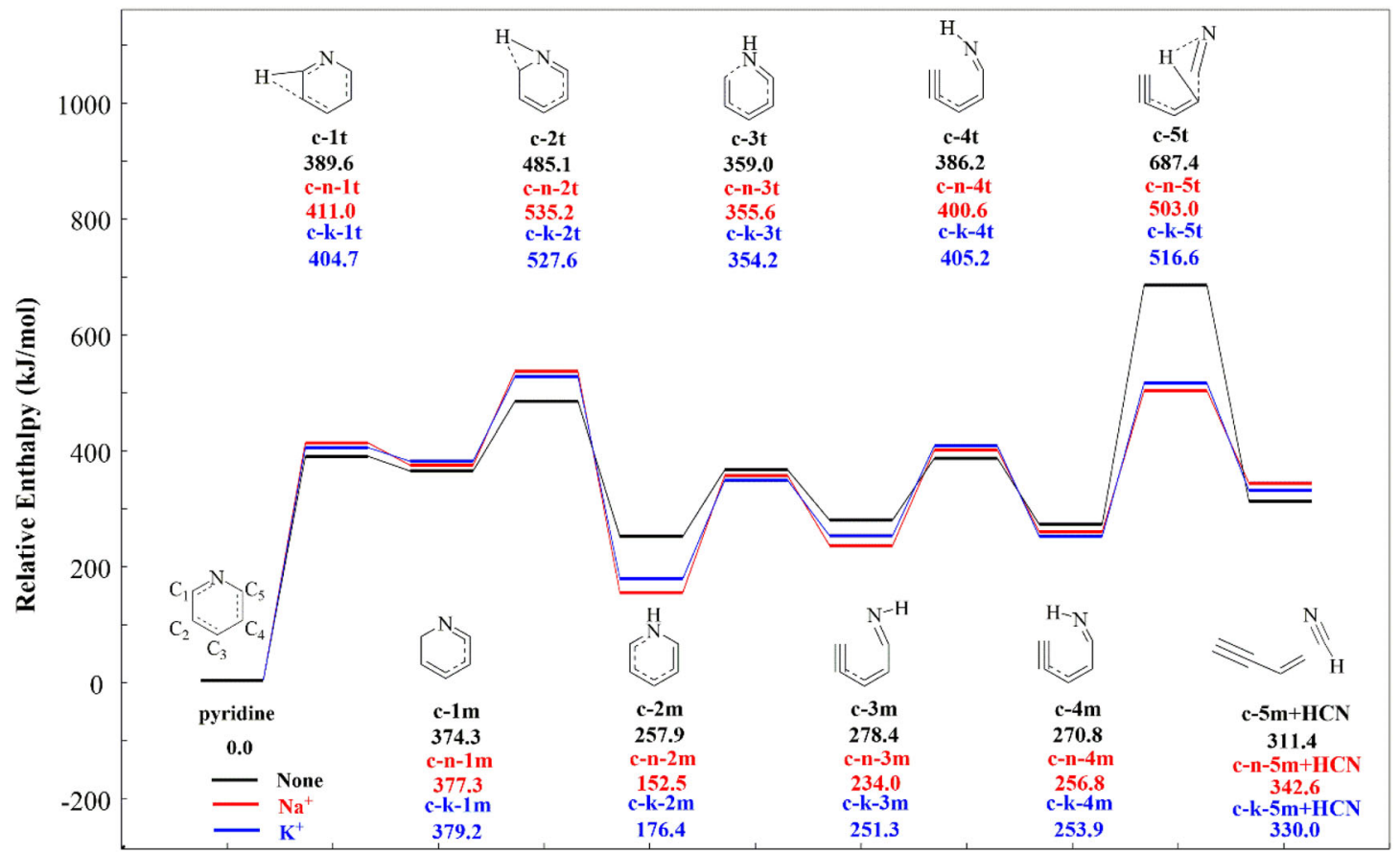

Fig. 4 Energy profiles of uncatalyzed and $\mathrm{Na}^{+} / \mathrm{K}^{+}$-catalyzed pyridine pyrolysis to form $\mathrm{HCN}$ via path-c (unit: $\mathrm{kJ} / \mathrm{mol}$ )

reactions are facilitated by the alkali metal ions, similar to in path-a. However, the alkali metal ions have little effect on other reactions that do not involve the rupture of $\mathrm{C}-\mathrm{C}$ bonds. The two alkali metal ions also alter the rate-determining step of path-c. In the uncatalyzed condition, the final step determines the reaction rate; in contrast, during $\mathrm{Na}^{+} / \mathrm{K}^{+}$-catalyzed pyridine pyrolysis, the second step of hydrogen transfer $\left(\mathrm{C}_{1}\right.$ to $\left.\mathrm{N}\right)$ is the rate-determining step. In summary, In summary, $\mathrm{Na}^{+}$and $\mathrm{K}^{+}$significantly promote $\mathrm{C}-\mathrm{C}$ bond breakage during pyridine pyrolysis to form $\mathrm{HCN}$, and $\mathrm{Na}^{+}$shows a greater catalytic effect than $\mathrm{K}^{+}$. 


\subsubsection{HCN formation via path-d}

Figure 5 shows the catalytic effects of $\mathrm{Na}^{+}$and $\mathrm{K}^{+}$on path-d. As mentioned above, the initial hydrogen transfer from $C_{3}$ to $C_{2}$ is hindered by the presence of alkali metal ions. The activation energy increases from $406.6 \mathrm{~kJ} / \mathrm{mol}$ (uncatalyzed) to $423.0 \mathrm{~kJ} / \mathrm{mol} \quad\left(\mathrm{Na}^{+}\right.$-catalyzed) and $419.5 \mathrm{~kJ} / \mathrm{mol}\left(\mathrm{K}^{+}\right.$-catalyzed). Subsequently, the $\mathrm{C}_{1}-\mathrm{N}$ bond breaks accompanied by hydrogen transfer from $\mathrm{C}_{5}$ to the $\mathrm{N}$ atom. Unsurprisingly, the activation energy $(660.5 \mathrm{~kJ} / \mathrm{mol})$ is greatly reduced by alkali ion catalysis to $433.3 \mathrm{~kJ} / \mathrm{mol}$ for $\mathrm{Na}^{+}$and $431.6 \mathrm{~kJ} / \mathrm{mol}$ for $\mathrm{K}^{+}$. The $\mathrm{H}$ atom bound to the $\mathrm{N}$ atom then migrates to the $\mathrm{C}_{4}$ position to form a $\mathrm{C} \equiv \mathrm{N}$ triple bond. Notably, the activation energy of this step is also greatly reduced under the catalysis of the two alkali metal ions. This reaction does not involve the breakage of a $\mathrm{C}-\mathrm{C}$ bond but a transformation from a double bond to a triple bond. The uncatalyzed activation energy is $587.1 \mathrm{~kJ} / \mathrm{mol}$; the activation energy under the $\mathrm{Na}^{+}$-catalyzed condition $(454.6 \mathrm{~kJ} / \mathrm{mol})$ is decreased by $132.5 \mathrm{~kJ} / \mathrm{mol}$, while that under the $\mathrm{K}^{+}$-catalyzed condition $(461.8 \mathrm{~kJ} / \mathrm{mol})$ is lowered by $125.3 \mathrm{~kJ} / \mathrm{mol}$. Similarly, $\mathrm{HCN}$ and $\mathrm{d}-4 \mathrm{~m}$ (vinylacetylene) are formed by a final breakage of the $\mathrm{C}_{4}-\mathrm{C}_{5}$ bond via hydrogen transfer with an activation energy of $620.9 \mathrm{~kJ} / \mathrm{mol}$. The activation energies under $\mathrm{Na}^{+}$and $\mathrm{K}^{+}$catalysis $(540.4$ and $550.6 \mathrm{~kJ} / \mathrm{mol}$, respectively) are 80.5 and $70.3 \mathrm{~kJ} / \mathrm{mol}$ lower than that without catalysis. Thus, $\mathrm{Na}^{+}$and $\mathrm{K}^{+}$significantly promote the final $\mathrm{C}-\mathrm{C}$ bond cleavage to form $\mathrm{HCN}$, with $\mathrm{Na}^{+}$ having a stronger effect than $\mathrm{K}^{+}$.

In the presence of alkali metal ions, both the scission of the $\mathrm{C}-\mathrm{C}$ bond and the formation of the triple bond from the double bond are facilitated by catalysis by $\mathrm{Na}^{+}$and $\mathrm{K}^{+}$. Additionally, whereas the second step (hydrogen transfer) is the rate-determining step of the uncatalyzed process, the second step (hydrogen transfer) is the rate-determining step of path-d under alkali metal catalysis. All in all, both $\mathrm{Na}^{+}$ and $\mathrm{K}^{+}$alter the rate-determining step of path-d, reduce the activation energy, and promote the formation of $\mathrm{HCN}$, with $\mathrm{Na}^{+}$having a greater influence than $\mathrm{K}^{+}$.

\subsubsection{HCN formation via path-e}

Figure 6 illustrates the energy profiles of path-e under the uncatalyzed, $\mathrm{Na}^{+}$-catalyzed, and $\mathrm{K}^{+}$-catalyzed conditions. First, the $\mathrm{H}$ atom at the $\mathrm{C}_{3}$ position of pyridine transfers to the $\mathrm{C}_{2}$ position to form e- $1 \mathrm{~m}$ via internal hydrogen transfer. In the absence of alkali metal ions, the transition state is e-1t, which has an activation energy of $389.4 \mathrm{~kJ} / \mathrm{mol}$. Both $\mathrm{Na}^{+}$and $\mathrm{K}^{+}$inhibit the internal hydrogen transfer reaction. The activation energy under $\mathrm{Na}^{+}$catalysis is $423.4 \mathrm{~kJ} / \mathrm{mol}$, which is $34.0 \mathrm{~kJ} / \mathrm{mol}$ higher than that without catalysis. $\mathrm{K}^{+}$ has a slightly weaker influence than $\mathrm{Na}^{+} ; \mathrm{K}^{+}$catalysis increases the activation energy to $418.0 \mathrm{~kJ} / \mathrm{mol}$. Next, the

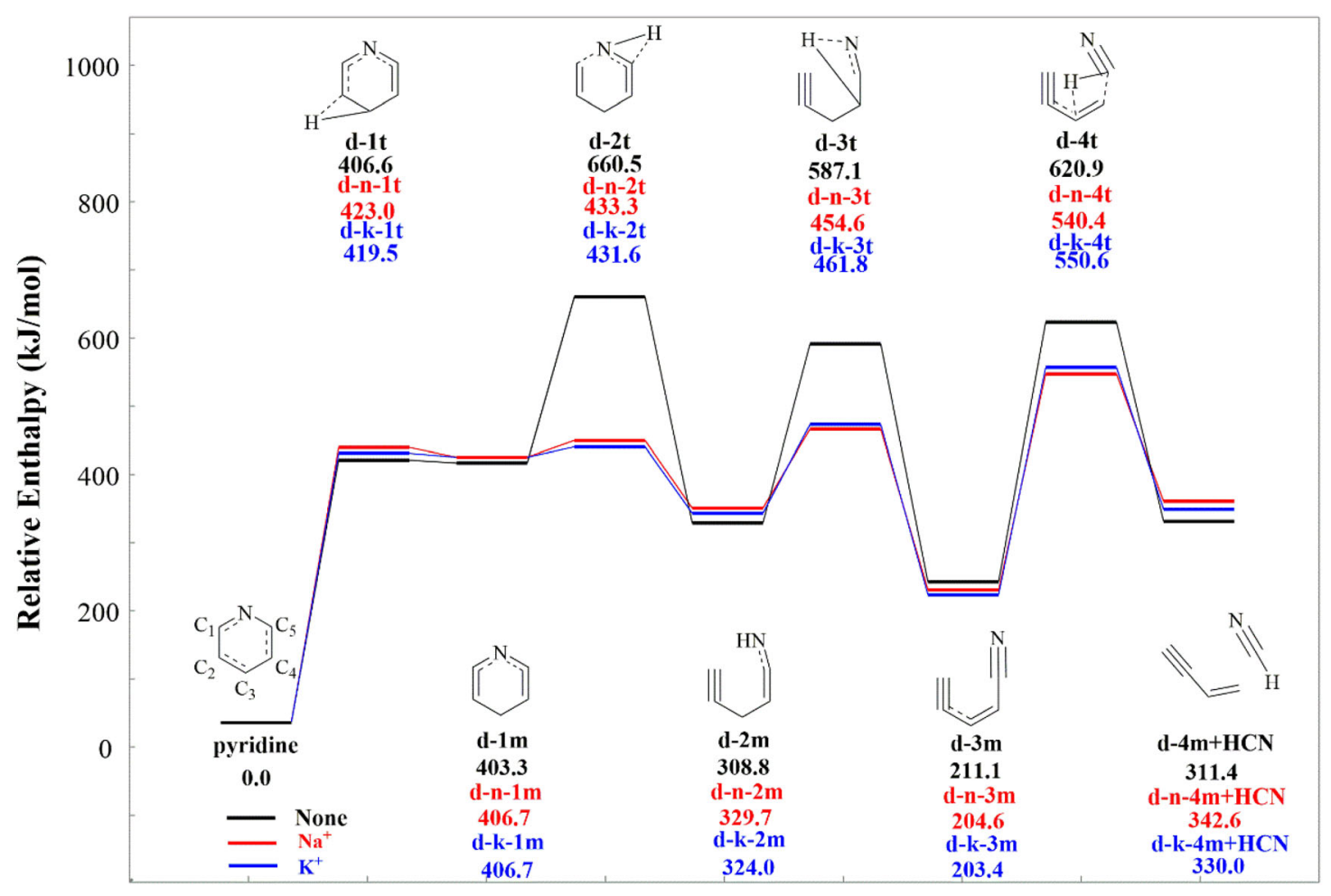

Fig. 5 Energy profiles of uncatalyzed and $\mathrm{Na}^{+} / \mathrm{K}^{+}$-catalyzed pyridine pyrolysis to form $\mathrm{HCN}$ via path-d (unit: $\mathrm{kJ} / \mathrm{mol}$ ) 


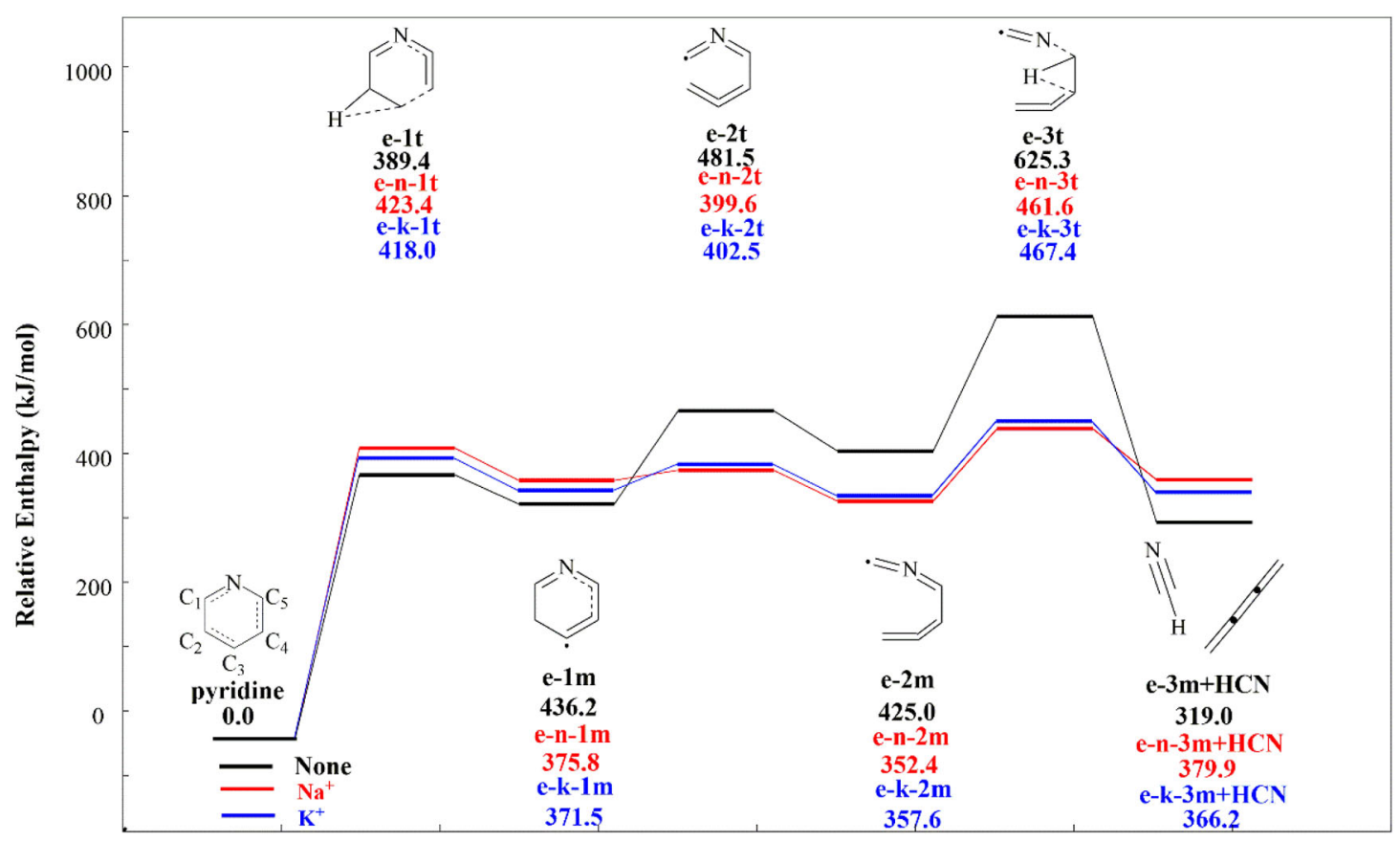

Fig. 6 Energy profiles of uncatalyzed and $\mathrm{Na}^{+} / \mathrm{K}^{+}$-catalyzed pyridine pyrolysis to form $\mathrm{HCN}$ via path-e (unit: $\mathrm{kJ} / \mathrm{mol}$ )

intermediate e-1 $\mathrm{m}$ undergoes a concerted ring-opening reaction to break the $\mathrm{C}_{1}-\mathrm{C}_{2}$ bond via the transition state e- $2 \mathrm{t}(481.5 \mathrm{~kJ} / \mathrm{mol})$. As for the $\mathrm{Na}^{+}$- or $\mathrm{K}^{+}$-catalyzed pyrolysis of pyridine, the activation energy is lowered to 399.6 or $402.5 \mathrm{~kJ} / \mathrm{mol}$, respectively. Different from the other four pathways, the breakage of the $\mathrm{C}_{5}-\mathrm{N}$ bond results in the formation of a $\mathrm{C} \equiv \mathrm{N}$ triple bond, producing $\mathrm{HCN}$ and e-3 m. Without catalysis, this final step determines the reaction rate of path-e, and the overall activation energy is $625.3 \mathrm{~kJ} / \mathrm{mol}$. The presence of $\mathrm{Na}^{+}$or $\mathrm{K}^{+}$significantly decreases the activation energy of this reaction by 163.7 or $157.9 \mathrm{~kJ} / \mathrm{mol}$, respectively. Even so, the final $\mathrm{C}-\mathrm{N}$ bond scission is still the rate-determining step, and the overall activation energy is 461.6 or $467.4 \mathrm{~kJ} / \mathrm{mol}$ less than that under the $\mathrm{Na}^{+}$- or $\mathrm{K}^{+}$-catalyzed condition, respectively.

The above calculation results indicate that alkali metal ions significantly promote the $\mathrm{C}-\mathrm{C}$ bond scission and formation of the $\mathrm{C} \equiv \mathrm{N}$ triple bond in path-e. $\mathrm{Na}^{+}$and $\mathrm{K}^{+}$ lower the overall activation energy for pyridine pyrolysis, further promoting the formation of $\mathrm{HCN}$. Overall, $\mathrm{Na}^{+}$has a slightly greater catalytic effect than $\mathrm{K}^{+}$.

The energy profiles of the above five pathways under the uncatalyzed, $\mathrm{Na}^{+}$-catalyzed, and $\mathrm{K}^{+}$-catalyzed conditions are compared in Fig. S2-S4 in Supplementary Material. Without catalysis, the most favorable pathway for $\mathrm{HCN}$ formation is path-a. In contrast, under the catalysis of $\mathrm{Na}^{+}$ or $\mathrm{K}^{+}$, path-e is the most favorable pathway. The presence of the two alkali metal ions alters the competitiveness of the possible $\mathrm{HCN}$ formation pathways and greatly decreases the energy barriers of the pyrolysis reactions, suggesting a promotion effect on HCN generation. This finding is consistent with the results of previous experimental studies (Li and Tan 2000; Yan et al. 2005; Liu and Guo 2017; Bai et al. 2019; Liu et al. 2019; Luo et al. 2019), attesting to the rationality of the computational results of the present work. Notably, the energetics of the above pathways are discussed based on enthalpy; however, the same trend was obtained when comparing the Gibbs free energies (Figs. S5-S7 in Supplementary Material).

The influence of temperature was examined by comparing the rate constants of the HCN generation pathways. According to Fig. 7, path-e has the largest rate constant in the temperature range from 273 to $973 \mathrm{~K}$, demonstrating the dominance of this pathway in HCN generation under $\mathrm{Na}^{+} / \mathrm{K}^{+}$catalysis. As the pyrolysis temperature increases, the advantage of path-e gradually weakens because the other four pathways have greater pre-exponential factors. The natural population analysis charges were calculated to further analyze the roles of $\mathrm{Na}^{+}$and $\mathrm{K}^{+}$at the electronic level (Figs. S8-S12 in Supplementary Material). As discussed in Sect. 3.1, $\mathrm{Na}^{+}$has a stronger effect than $\mathrm{K}^{+}$on all reactions except hydrogen transfer from $\mathrm{C}_{1}$ to $\mathrm{C}_{2}$, which can be ascribed to the distinct variations in charge induced by $\mathrm{Na}^{+}$and $\mathrm{K}^{+}$. For the initial hydrogen transfer from $\mathrm{C}_{1}$ to $\mathrm{C}_{2}$, the change in charge for the $\mathrm{H}$ acceptor (the $\mathrm{C}_{2}$ atom) is larger in the presence of $\mathrm{K}^{+}$than in the presence of $\mathrm{Na}^{+}$. In contrast, for the other initial hydrogen transfer reactions, the variation in charge for the $\mathrm{H}$ acceptor is larger for $\mathrm{Na}^{+}$than for $\mathrm{K}^{+}$. In addition, $\mathrm{Na}^{+} / \mathrm{K}^{+}$has little effect on the molecular structures but a large influence on 

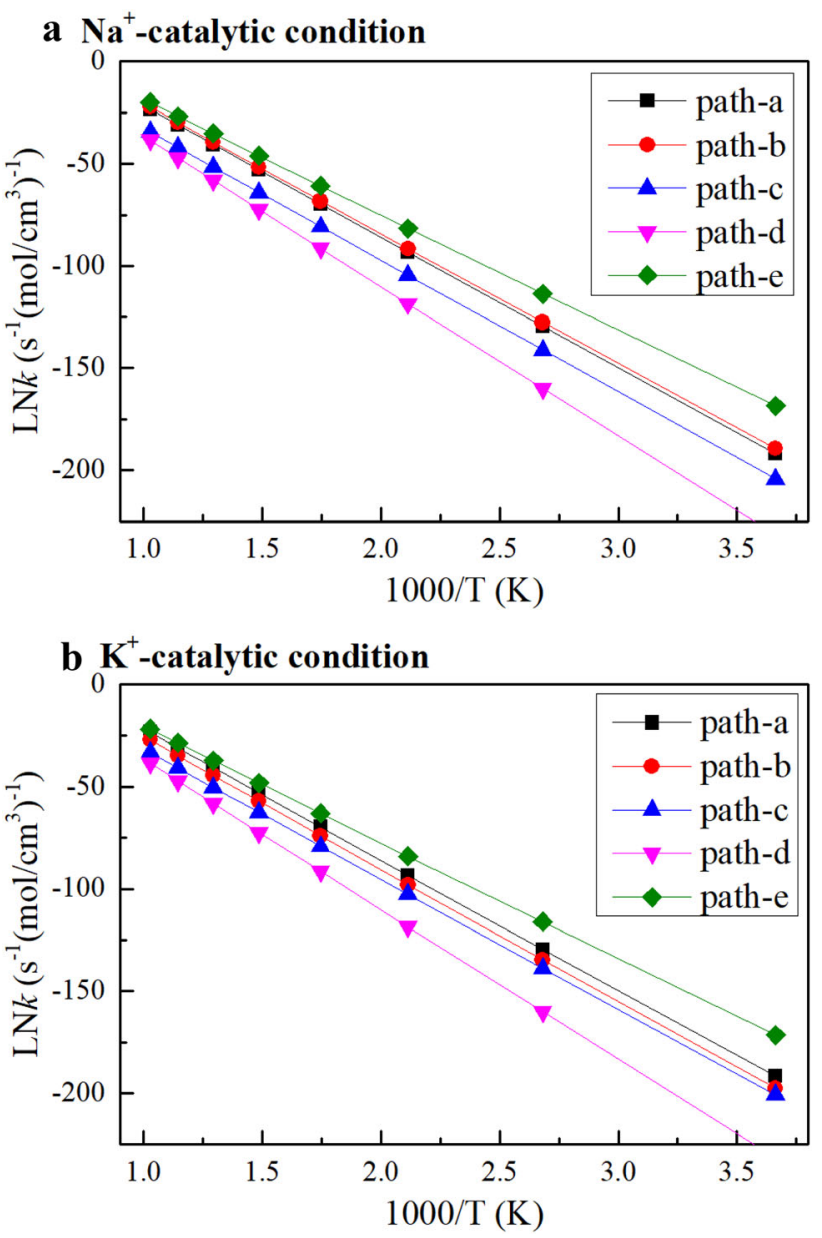

Fig. 7 Comparison of the reaction rate constants of the ratedetermining steps of different pathways in the temperature range of 293-973 K under the a $\mathrm{Na}^{+}$-catalyzed condition and $\mathbf{b} \mathrm{K}^{+}$-catalyzed condition

charge redistribution. Hence, the energetic changes are strongly correlated to the charge variation induced by the two alkali metal ions.

\section{Conclusions}

The present work explored the roles of $\mathrm{Na}^{+}$and $\mathrm{K}^{+}$in the pyrolysis of pyridine to produce HCN using DFT calculations. Based on the computational results, the effects of the two alkali metal ions can be summarized as follows.

$\mathrm{Na}^{+}$and $\mathrm{K}^{+}$have dual roles in the initial hydrogen transfer reactions. Both ions facilitate the migration from $\mathrm{C}_{1}$ to $\mathrm{N}$ or $\mathrm{C}_{2}$ by reducing the activation energy. For Reaction $\mathrm{b}$ (hydrogen transfer from $\mathrm{C}_{1}$ to $\mathrm{C}_{2}$ ), the activation energy is decreased by 69.4 and $71.9 \mathrm{~kJ} / \mathrm{mol}$ under the catalysis of $\mathrm{Na}^{+}$and $\mathrm{K}^{+}$, respectively. In contrast, the activation energies of the other initial hydrogen transfer reactions $\left(\mathrm{C}_{2}\right.$ to $\mathrm{C}_{1}, \mathrm{C}_{2}$ to $\mathrm{C}_{3}$, and $\mathrm{C}_{3}$ to $\left.\mathrm{C}_{2}\right)$ are increased by $13.1-54.0 \mathrm{~kJ} / \mathrm{mol}$. For all reactions except hydrogen transfer from $\mathrm{C}_{1}$ to $\mathrm{C}_{2}, \mathrm{Na}^{+}$has a greater effect than $\mathrm{K}^{+}$ due to the distinct variations in charge induced by these two alkali metal ions.

Among the elementary reactions involved in the formation of $\mathrm{HCN}$ during pyridine pyrolysis, $\mathrm{Na}^{+}$and $\mathrm{K}^{+}$ significantly decrease the activation energies of $\mathrm{C}-\mathrm{C}$ bond breakage and triple bond formation. In contrast, the other reactions are only slightly promoted by the two alkali metal ions, and the isomerization reactions are even hindered by them. The different energetic effects essentially result from the distinct charge distributions induced by the two alkali ions.

The presence of $\mathrm{Na}^{+}$and $\mathrm{K}^{+}$significantly lowers the overall activation energy and even alters the rate-determining step for both path-c and path-d. Hence, the formation of $\mathrm{HCN}$ is promoted by the presence of $\mathrm{Na}^{+}$or $\mathrm{K}^{+}$. Due to the different effects of $\mathrm{Na}^{+} / \mathrm{K}^{+}$on the individual elementary reactions and pathways, the competitiveness of the possible pathways is altered by these ions. Under the uncatalyzed condition, path-b, which involves two hydrogen transfer reactions along with $\mathrm{C}-\mathrm{C}$ bond breakage and isomerization, is the most favorable. In the presence of $\mathrm{Na}^{+} / \mathrm{K}^{+}$, the most favorable pathway changes to path-e, in which pyridine is decomposed via hydrogen transfer reactions, concerted ring opening, and $\mathrm{C}-\mathrm{N}$ bond scission.

Therefore, the inclusion of $\mathrm{Na}^{+}$and $\mathrm{K}^{+}$in coal should be considered for source-control $\mathrm{NO}_{x}$ abatement techniques.

Acknowledgments This work was supported by the National Key Research Development Program of China (2017YFB0601900), National Nature Science Foundation of China (51806220, 51922040), China Postdoctoral Science Foundation (2019TQ0091), Grants from Fok Ying Tung Education Foundation (161051), and Fundamental Research Funds for the Central Universities (2020MS020, 2020DF01).

\section{Declarations}

Conflict of interest All authors certify that they have no affiliations with or involvement in any organization or entity with any financial interest or non-financial interest in the subject matter or materials discussed in this manuscript.

Open Access This article is licensed under a Creative Commons Attribution 4.0 International License, which permits use, sharing, adaptation, distribution and reproduction in any medium or format, as long as you give appropriate credit to the original author(s) and the source, provide a link to the Creative Commons licence, and indicate if changes were made. The images or other third party material in this article are included in the article's Creative Commons licence, unless indicated otherwise in a credit line to the material. If material is not included in the article's Creative Commons licence and your intended use is not permitted by statutory regulation or exceeds the permitted use, you will need to obtain permission directly from the copyright holder. To view a copy of this licence, visit http://creativecommons. org/licenses/by/4.0/. 


\section{References}

Adamczyk WP, Werle S, Ryfa A (2014) Application of the computational method for predicting $\mathrm{NO}_{x}$ reduction within large scale coal-fired boiler. Appl Therm Eng 73:343-350

Bai Y, Lv P, Li F, Song X, Su W, Yu G (2019) Investigation into Ca/ $\mathrm{Na}$ compounds catalyzed coal pyrolysis and char gasification with steam. Energy Convers Manag 184:172-179

Beste A, Buchanan AC III (2009) Computational study of bond dissociation enthalpies for lignin model compounds. Substituent effects in phenethyl phenyl ethers. J Organ Chem 74:2837-2841

Chu F, Su M, Yang G (2020) Heat and mass transfer characteristics of ammonia regeneration in packed column. Appl Therm Eng 176:115405

Dennington R, Keith T, Millam J (2016) GaussView, Version6. Semichem Inc., Shawnee Mission

Durie R (2013) The science of Victorian brown coal: structure, properties and consequences for utilization. Butterworth-Heinemann, Oxford

Franklin HD, Cosway RG, Peters WA, Howard JB (1983) Effects of cations on the rapid pyrolysis of a Wyodak subbituminous coal. Ind Eng Chem Process Des Dev 22:39-42

Frisch MJ, Trucks GW, Schlegel HB, Scuseria GE, Robb MA, Cheeseman JR, Scalmani G, Barone V, Petersson GA, Nakatsuji $\mathrm{H}$, Li X, Caricato M, Marenich AV, Bloino J, Janesko BG, Gomperts R, Mennucci B, Hratchian HP, Ortiz JV, Izmaylov AF, Sonnenberg JL, Williams-Young D, Ding F, Lipparini F, Egidi F, Goings J, Peng B, Petrone A, Henderson T, Ranasinghe D, Zakrzewski VG, Gao J, Rega N, Zheng G, Liang W, Hada M, Ehara M, Toyota K, Fukuda R, Hasegawa J, Ishida M, Nakajima $\mathrm{T}$, Honda $\mathrm{Y}$, Kitao $\mathrm{O}$, Nakai $\mathrm{H}$, Vreven $\mathrm{T}$, Throssell $\mathrm{K}$, Montgomery JA Jr, Peralta JE, Ogliaro F, Bearpark MJ, Heyd JJ, Brothers EN, Kudin KN, Staroverov VN, Keith TA, Kobayashi R, Normand J, Raghavachari K, Rendell AP, Burant JC, Iyengar SS, Tomasi J, Cossi M, Millam JM, Klene M, Adamo C, Cammi R, Ochterski JW, Martin RL, Morokuma K, Farkas O, Foresman JB, Fox DJ (2016) Gaussian 16, Revision B.01. Gaussian, Inc., Wallingford

Glukhovtsev MN, Bach RD, Nagel CJ (1997) Performance of the B3LYP/ECP DFT calculations of iron-containing compounds. J Phys Chem A 101:316-323

Gu XH, Mao XF, Zhao Y, Li WB, Zhang XJ (2013) Study on the basic nitrogen compounds from coal-derived oil. J Coal Sci Eng (China) 19:83-89

Hämäläinen JP, Aho MJ, Tummavuori JL (1994) Formation of nitrogen oxides from fuel- $\mathrm{N}$ through $\mathrm{HCN}$ and $\mathrm{NH}_{3}$ : a modelcompound study. Fuel 73:1894-1898

Hong X, Zhang TC, Zhang LD, Qi F (2013) Identification of intermediates in pyridine pyrolysis with molecular-beam mass spectrometry and tunable synchrotron VUV photoionization. Chin J Chem Phys 22:204

Houser TJ, Hull M, Always RM, Biftu T (1980) Kinetics of formation of $\mathrm{HCN}$ during pyridine pyrolysis. Int J Chem Kinet 12:569-574

Ikeda E, Mackie JC (1995) Thermal decomposition of two coal model compounds-pyridine and 2-picoline. Kinetics and product distributions. J Anal Appl Pyrolysis 34:47-63

Jiang X, Lu Q, Hu B, Liu J, Dong C, Yang Y (2017) A comprehensive study on pyrolysis mechanism of substituted $\beta-\mathrm{O}-4$ type lignin dimers. Int J Mol Sci 18:2364-2377

Kampa M, Castanas E (2008) Human health effects of air pollution. Environ Pollut 151:362-367

Koger S, Bockhorn $\mathrm{H}$ (2005) $\mathrm{NO}_{x}$ formation from ammonia, hydrogen cyanide, pyrrole, and caprolactam under incinerator conditions. Proceed Combust Inst 30:1201-1209
Li CZ, Tan LL (2000) Formation of $\mathrm{NO}_{x}$ and $\mathrm{SO}_{x}$ precursors during the pyrolysis of coal and biomass. Part III. Further discussion on the formation of $\mathrm{HCN}$ and $\mathrm{NH}_{3}$ during pyrolysis. Fuel 79:1899-1906

Ling LX, Zhang RG, Wang BJ, Xie KC (2009) Density functional theory study on the pyrolysis mechanism of thiophene in coal. J Mol Struct 905:8-12

Liu J, Guo X (2017) ReaxFF molecular dynamics simulation of pyrolysis and combustion of pyridine. Fuel Process Technol 161:107-115

Liu R, Huang TTS, Tittle J, Xia D (2000) A theoretical investigation of the decomposition mechanism of pyridyl radicals. J Phys Chem A 104:8368-8374

Liu J, Lu Q, Jiang XY, Hu B, Zhang XL, Dong CQ, Yang YP (2018a) Theoretical investigation of the formation mechanism of $\mathrm{NH}_{3}$ and $\mathrm{HCN}$ during pyrrole pyrolysis: the effect of $\mathrm{H}_{2} \mathrm{O}$. Molecules 23:711

Liu J, Zhang X, Lu Q, Shaw A, Hu B, Jiang X, Dong C (2018b) Mechanism study on the effect of alkali metal ions on the formation of $\mathrm{HCN}$ as $\mathrm{NO}_{x}$ precursor during coal pyrolysis. J Energy Inst 92:604-612

Liu J, Zhang X, Lu Q, Shaw A, Hu B, Jiang X, Dong C (2019) Mechanism study on the effect of alkali metal ions on the formation of $\mathrm{HCN}$ as $\mathrm{NO}_{x}$ precursor during coal pyrolysis. J Energy Inst 92(3):604-612

Liu S, Wu Y, Zhou C, Wu J, Zhang Y (2020a) Study on the CO formation mechanism during coal ambient temperature oxidation. Energies 13:2587

Liu J, Zhang X, Hu B, Lu Q, Liu DJ, Dong CQ, Yang YP (2020b) Formation mechanism of $\mathrm{HCN}$ and $\mathrm{NH}_{3}$ during indole payrolysis: a theoretical DFT study. J Energy Inst 93:649-657

Luo J, Zou C, He Y, Jing H, Cheng S (2019) The characteristics and mechanism of $\mathrm{NO}$ formation during pyridine oxidation in $\mathrm{O}_{2} / \mathrm{N}_{2}$ and $\mathrm{O}_{2} / \mathrm{CO}_{2}$ atmospheres. Energy 187:115954

Ma Z, Zhang Y, Li C, Yang Y, Zhang W, Zhao C, Wang S (2019) $\mathrm{N}$-doping of biomass by ammonia $\left(\mathrm{NH}_{3}\right)$ torrefaction pretreatment for the production of renewable $\mathrm{N}$-containing chemicals by fast pyrolysis. Bioresour Technol 292:122034

Mackie JC, Colket MB, Nelson PF (1990) Shock tube pyrolysis of pyridine. J Phys Chem 94:4099-4106

MacNamara JP, Simmie JM (2003) The high temperature oxidation of pyrrole and pyridine; ignition delay times measured behind reflected shock waves. Combust Flame 133:231-239

Mai TVT, Nguyen HT, Huynh LK (2020) Ab initio kinetic mechanism of $\mathrm{OH}$-initiated atmospheric oxidation of pyrrole. Chemosphere 263:127850

Molina A, Eddings EG, Pershing D, Sarofim A (2000) Char nitrogen conversion: implications to emissions from coal-fired utility boilers. Prog Energy Combust Sci 26:507-531

Ninomiya Y, Dong Z, Suzuki Y, Koketsu J (2000) Theoretical study on the thermal decomposition of pyridine. Fuel 79:449-457

Ohtsuka Y, Zhiheng W, Furimsky E (1997) Effect of alkali and alkaline earth metals on nitrogen release during temperature programmed pyrolysis of coal. Fuel 76:1361-1367

Tsiliyannis CA (2016) Emissions and power losses due to biofuel or biomass nitrogen: assessment and prevention mechanisms. Energy Fuels 30:9396-9408

Wood BJ, Sancier KM (1984) The mechanism of the catalytic gasification of coal char: a critical review. Catal Rev Sci Eng 26:233-279

Wu CL, Cao Y, Dong ZB, Cheng CM, Li HX, Pan WP (2010) Mercury speciation and removal across full-scale wet FGD systems at coal-fired power plants. J Coal Sci Eng (China) $16: 82-87$ 
Yan X, Che D, Xu T (2005) Effect of rank, temperatures and inherent minerals on nitrogen emissions during coal pyrolysis in a fixed bed reactor. Fuel Process Tehcnol 86:739-756

Ye C, Wang Q, Zheng Y, Li G, Zhang Z, Luo Z (2019) Technoeconomic analysis of methanol and electricity poly-generation system based on coal partial gasification. Energy 185:624-632
Zhang K, Li Y, Yuan T, Cai J, Glarborg P, Qi F (2011) An experimental and kinetic modeling study of premixed nitromethane flames at low pressure. Proc Combust Inst 33:407-414 